\title{
Analysis on the Freehand Brushwork of Chinese Painting and the Native Oil Painting Language
}

\author{
Limin Fan \\ School of Art \\ Xuzhou University of Engineering \\ Xuzhou, China
}

\begin{abstract}
Oil painting is an exotic painting introduced to China at the beginning of the 20th century, and then has been blended and collided with traditional Chinese culture. In this process, oil painting also forms an independent artistic language, which is different from western painting, - freehand brushwork, explored by Chinese painters by reference, absorption and continuous innovation. This paper introduces the origin and characteristics of Chinese oil painting "freehand" and analyzes the main factors that influence the "freehand brushwork" of Chinese oil painting and its future development trend.
\end{abstract}

Keywords-oil painting language; freehand brushwork; artistic features

\section{INTRODUCTION}

The subjectivity of the expressionist painting is the subjective worship of the self, which reveals the soul fusion of the artist and the painting. The expressionist painter believes that "the world exists, and to merely copy the world is meaningless", the true art should be "not the reality, but the spirit", "the expression, not the reproduction". The whole function of the artist is in the subjective illusion, and having grasped the illusion means having grasped the meaning of the world. The expressionist painting abandons the artistic principle of classical realism and pursues a reality of deformation. The expressionist demands that under the action of subjective emotion, the reality should be distorted and exaggerated, and the reality can be transformed into magic, and it pursues the reality of the distortion of the spirit. Expressionism regards painting as a tool for expressing pure emotion and the inner world. They emphasize the absoluteness of self-perception and deny the rationalism. They regards the intuition as the only way to understand the world, and they want to use art to express their anger and passion, and to show the inner contradictions of contemporary people. Since the appearance of expressive oil painting in China, it has not formed its own cultural standard position. As a result, in order to distinguish itself from the western expressionist painting, it is necessary to establish the aesthetic value system of the nation and draw on the expressive painting language in the freehand brushwork. The expressive painting language in freehand brushwork derives from the spiritual resources of Chinese traditional culture, and is the factor that constitutes the independence and uniqueness of Chinese painting. This paper puts forward the notion of the freehand brushwork of Chinese painting so as to establish China's cultural standard position and to establish a cultural spirit that connects with traditional Chinese culture in the exploration of the painting language of expressive oil painting. Chinese oil painting expressionism tends to pay attention to the essence and value of human beings, attaching importance to human's spiritual belief and human dignity. The author believes that in the expressive oil painting, it is a favorable factor for Chinese expressionist painting to blend in the freehand brushwork language with Chinese spirit. From the perspective of history, this paper combines with the current theory, and extends the edge scope of art history as the main method to explore the evolution and existence of Chinese expressive oil painting.

\section{THE CAUSES OF THE FreEHAND BRUSHWORK IN CHINA}

Due to the development of economy and the development of people's vision, the problems faced by Chinese oil painting are becoming increasingly prominent. In view of the current situation of Chinese oil painting, many artists have begun a new exploration. How to make Chinese oil painting meet the needs of local specific situation has become a concern of the art circles. Particularly, since the reform and opening up, the change of Chinese politics and the rapid development of China's economy provide more opportunities for communications between the west and China. As the release of works of various art genres and forms from abroad, European oil painting of various schools and thoughts has surged into China, which has provided Chinese oil painters with more opportunities to contact and understand western art schools and new ideas of art and which has promoted Chinese oil painters to better use it as a reference for changing their artistic style and renewing their creative thinking. With the continuous deepening of Chinese oil painting creation and the continuous emergence of excellent works, oil painting creation has been vigorously developed in China. Creativity in oil painting is the eternal theme of art creation. Chinese oil painters have been insisting on innovating in their study and reference because of their unique cultural heritage, and gradually formed the oil painting art language with Chinese cultural characteristics. The "freehand brushwork" of oil painting has become an important way for Chinese painters to explore art. 


\section{THE REASON TO PROMOTE THE FREEHAND BRUSHWORK OF CHINESE PAINTING IN THE LOCAL OIL PAINTING LANGUAGE}

There is a unique spiritual appeal in Chinese painting, which is inspiring. It reminds people of the spirit of the shake of the five famous Chinese mountains. The state of vitality, as if the author's human feelings are materialized in the picture, and has been put clean to people through brushes. The freehand expression of the oil painting language emphasizes the subjective emotion of the person, while the form of objective object in the human brain only exists as a subjective existence. From the perspective of expression form, subjective analytic expression may deviate from the objective object, which is a spontaneous way of thinking from the inside out. The combination of "things" and "I" endows freehand oil painting with unique charm and magic. The freehand expression language of Chinese oil painting is because it integrates Chinese traditional culture into the painting of western oil painting. The most striking features of its expressive language are: 1 . Not to seek the realistic representation of the surface form of objective things, but to seek the in-depth study of objective things, and form the state of the "real" after integrating with its own thoughts and emotions. 2. After the pursuit of the external appearance of a lot of modeling elements, it forms a visual image which has a rich emotional connotation, displays inner vitality and has a form aesthetic feeling. The oil painting language is the unique symbol of every painter. Qi Baishi has a famous saying, saying that, "the wonderful is between similarity and dissimilarity, being too similar falls to the kitsch, being dissimilar descends to be deceiving the world." What he said was actually an artistic expression of his point of view. From the perspective of artistic expression, being "too similar" is lack of generalization, which makes the author prone to be restrained, or makes the expressive language difficult to be played to full use. Therefore, the appearance in the works is very rigid. However, the lack of a credible visual image makes it less convincing. Therefore, the artist is free to play in a "degree".

\section{THE EXPRESSION CHARACTER AND SPIRITUAL CONNOTATION OF CHINESE PAINTING IN THE NATIVE OIL PAINTING LANGUAGE}

"Freehand" is the unique term and artistic expression law of Chinese art theory. Under such law, artists are generally asked to show their pictures focusing on artistic conception, and pursue the similarity in spirit but not in appearance. They ought to reflect the reality out of the virtue, and pursue the atheistic interest of the vigor and romantic charm. Freehand brushwork, with its flowing brush and flowing ink, has become the most beautiful painting in traditional Chinese painting. In contrast with the brush painting, it can directly reflect the charm of the scene and the feelings of the author. In traditional Chinese painting, this characteristic artistic expression technique combines with oil painting creation, resulting in Chinese freehand painting. Freehand brushwork is a unique aesthetic factor of Chinese traditional culture. It pursues the resonance between the mind and spirit based on Chinese people's basic view of the form and color in the universe, and through specific content description and the expression of the ink. The so-called freehand brushwork is to express emotions through the outside scenery, an organic combination between the description of the realistic world and the emotional expressions of the inner thoughts. It is the outcome of the inner world and the outside world, which is the way of thinking and aesthetic interest different from that of the western and is formed by Chinese long-time history and deep cultural deposits. Freehand brushwork is a high level of art in Chinese painting, and is pursued by Chinese painters, which reveals the unique aesthetic interest of Chinese painting. The freehand brushwork in Chinese painting is not defined by painting tools, or the speed of finishing a picture, nor simply the vivid imitation. Only the inner spirit connotation has true meaning and can reflect the deep deposits of Chinese national culture. "Freehand" has combined western oil painting with Chinese traditional culture and has created a path of nationalization of oil painting. In other words, Chinese freehand painting is the exchange and fusion of Chinese traditional culture and western culture. In the middle and late fifties, the artistic creation rules have once appeared in the paintings of freehand brushwork. For example, the expression program of Chinese painting, single line painting, mobile perspective, blank screen, inscription seal, etc. But the exploration of the art field requires a deeper level of research, rather than a superficial imitation. As a fertile soil for the development of freehand brushwork, the long culture of the Chinese nation provides rich nourishment for the exploration and development of freehand painting. Only by further deepening the understanding of traditional culture and the spiritual connotation of image freehand, can we better realize the organic combination of oil painting and traditional Chinese culture.

\section{CONCLUSION}

Chinese oil painters have a little resonance with western expressionism in their ideas and tastes because of their expressive brushwork. This has prompted some oil painters in China to explore in the direction of freehand, and allows painters to express their inner feelings and spiritual callings in their own unique forms. As a result, oil painters regard painting and performance as a whole cultural appeal. Because of freehand brushwork, many oil painting artists have gained a greater freedom to create at different degrees of performance. After substantial practice and research, they have integrated freehand oil painting with national culture and gradually attract people's attention, thus provides its nationals with a broad space of and the great prospect of Chinese national oil painting. Chinese oil painting has its own uniqueness because of its rich traditional culture and folk culture. Therefore, Chinese oil painting will be more colorful and more Chinese-like, which not only belongs to China but also belongs to the world. Freehand painting attracts more and more young painters to explore their unique aesthetic ideas, and gradually formed the perfect creation method nourished by Chinese culture and idea, which carries forward the freehand brushwork of traditional Chinese painting in the painting of foreign paintings. As a unique oil painting genre in the world, China's domestic oil painting, which combines Chinese painting freehand brushwork, will surely become the shining pearl of the world. 


\section{REFERENCES}

[1] Tang Le, On the innovation and artistic creation of oil painting language, [J],Sichuan Opera, 2016(12):50-52

[2] Zhao Kun, Liu Wei, A study on the freehand brushwork of contemporary Chinese oil painting, $[\mathrm{J}]$, The Mass of Literature and Art, 2017(24):112-113

[3] Li Qian, Oil painting language, [J]The Mass of Literature and Art, 2017(02):117

[4] RenShuo, The choice of individualized oil painting language in modern oil painting,[J] Big Stage, 2014(01):34-35.

[5] BianXiaoqiang, On the importance of the oil painting language[J].Grand View of Art,2006(12):108-109.

[6] Yang Shuang, Research on the development and aesthetic value of contemporary Chinese oil painting language $[\mathrm{J}]$. Mass Literature,2015(16):137-138.

[7] Zhou Libin. Exploration of the subjectivity of oil painting language expression [J]. Art Technology,2016,29(11):206

[8] Ma Jie. The importance of oil painting language to oil painting creation [J]. Art Education Research,2015(07):26.

[9] Tang Hua. A brief analysis on the inheritance and development of national painting language in Chinese oil painting [J]. Grand View of Art,2016(04):76.

[10] Li Jianzhong. The linguistic trend of Chinese contemporary freehand brushwork [J]. RongBaozhai, 2017(10):228-229.

[11] Wang anshuang. Research on image oil painting language [J]. Art Education Research,2012(07):35.

[12] Wang Hailing. A tentative study on the freehand brushwork of oil painting [D]. Sichuan Normal University,2010.

[13] Wang Guangyi. The characteristics of the linguistic form of image oil painting [J]. Grand View of Art,2011(09):48.

[14] Wei Yuncheng, Chinese character of the knife of oil painting language [J]. Art Research,2008(04):123-124

[15] Wang Zutang. The new development of "oil painting nationalization" [J]. Theory and Creation,2006(04):109-110.

[16] He Shufang. Research on Chinese contemporary image oil painting [J]. Grand Stage,2014(10):41-42. 